\title{
A MULTICRITERIA GROUP DECISION MODEL AGGREGATING THE PREFERENCES OF DECISION-MAKERS BASED ON ELECTRE METHODS
}

\author{
Luciana Hazin Alencar \\ Adiel Teixeira de Almeida* \\ Danielle Costa Morais \\ Federal University of Pernambuco \\ Recife - PE, Brazil \\ almeidaatd@gmail.com \\ * Corresponding author / autor para quem as correspondências devem ser encaminhadas \\ Recebido em 12/2008; aceito em 03/2010 após 1 revisão \\ Received December 2008; accepted March 2010 after one revision
}

\begin{abstract}
Often decisions taken in organizations are made by a group of people, and in order to build a collective decision, the preferences of individuals must be considered. The two most useful approaches to aggregating individual preferences are the aggregation of individual judgments and the aggregation of individual priorities. This paper focuses on the latter approach and proposes a multicriteria group decision model in situations where there is no information with regard to the relative importance of the decision-makers. This model includes three stages. In the first, the ELECTRE II method is applied so as to obtain the individual rankings. In the second stage, a global matrix of alternatives versus decisionmakers is built up using the results from the previous stage. Finally, the third stage aggregates the individual preferences by applying the ELECTRE IV method and the final collective evaluation is undertaken. A numerical application is presented to illustrate the model.
\end{abstract}

Keywords: group decision; ELECTRE II; ELECTRE IV; multicriteria decision aid.

\section{Resumo}

Grande parte das decisões tomadas em uma organização envolve um grupo de pessoas. Nesse sentido é necessária a existência de metodologias adequadas que dêem suporte à tomada de decisão em grupo, tratando de forma coerente as avaliações e preferências de todos os decisores envolvidos nesse processo. Há duas abordagens utilizadas para decisão em grupo: a agregação dos julgamentos individuais e a agregação das prioridades individuais. Este trabalho foca na segunda abordagem propondo um modelo para decisão em grupo nas situações em que não se tem informação a respeito da importância dos decisores. Nesse modelo o método ELECTRE II é utilizado no primeiro momento e o método ELECTRE IV é utilizado no segundo momento, quando se faz a avaliação coletiva dos decisores. Uma aplicação numérica é apresentada para ilustrar o modelo.

Palavras-chave: decisão em grupo; ELECTRE II; ELECTRE IV; apoio multicritério a decisão. 


\section{Introduction}

Due to the ever-increasing complexity of socioeconomic environments, it is very difficult for only one decision-maker (DM) to consider all the important aspects of a problem (Kim \& Ahn, 1999). Thus, most decisions in an organization, whether public or private, are made by a group of people. This change of how to focus on the problem, i.e. the focus moves from that of one decision-maker to that of a group of people, introduces the important issue of how best to aggregate the decision-makers' preference structures. The analysis should be extended in order to consider, somehow, the preference structure of each one of the group members, their different perceptions of the consequences and their several aspirations.

According to Matsatsinis et al. (2005) supporting group decision-making becomes intensely difficult due to the presence of multiple actors, each with their own perceptions on the way the problem should be handled and the decision made. From such a perspective, a group decision can be understood as the reduction of different individual preferences into a joint set of data that expresses a single collective preference (Jelassi et al., 1990).

Currently, various authors have been studying group decision making which is thus an indication of its relevance (Alencar \& Almeida, 2008; Humphreys \& Garrick, 2006; Beynon, 2006; Colson, 2000; Costa et al. 2003; Matsatsinis et al., 2005; Leyva-López \& Fernández-González, 2003; Easley et al., 2000; Clímaco \& Dias, 2005; Dias \& Clímaco, 2000; Morais \& Almeida, 2007).

According to Forman \& Peniwati (1998), the two basic ways for aggregating individual preferences into a group preference depend on whether the group is assumed to act together as a unit (for instance, a group of departmental heads who meet to set corporate policy), or as separate individuals (for instance, a group consisting of representative electoral constituencies demanding reform in water resources management, each with his/her own perceptions); in other words, it depends on whether the group members engage in discussion either to achieve a consensus or to express their own preferences.

Given such a perspective, what is needed is an appropriate methodology to support group decision-making, which deals coherently with the evaluation and preferences of all members involved in the process. Therefore, this paper sets out to present a multicriteria group decision model, focusing on the situation where the decision-makers act in accordance with their own interests and there is no information about their relative importance to each other. First of all, the ELECTRE II method is applied to obtain the rankings of alternatives for each decision-maker. Thereafter, the individual decision-makers' preferences will comprise the evaluations of the matrix of alternatives versus those of the decision-makers. In the last stage, the ELECTRE IV method is applied, and the final ranking of the alternatives is reached.

This paper is structured into six sections: section 1 contextualizes the group decision and defines the objective of the study; section 2 gives a brief review of the literature on group decision models; section 3 summarizes the Electre methods; section 4 presents the multicriteria group decision model with an aggregation of the decision-makers' evaluations of the alternatives; in section 5 a numerical application of the model is presented and section 6 gives the conclusions of the study. 


\section{Group Decision Models}

Some models for tackling group decision problems that have already been drawn up are described below.

Leyva-López \& Fernández-González (2003) developed the ELECTRE GD for group decision which is an extension of ELECTRE III. They use a genetic algorithm to explore the outranking relation, derived from the ideas of ELECTRE related to concordance, discordance, veto and incomparability. Two stages are used: (1) ELECTRE III is used to build the outranking relation, and the genetic algorithm developed by the authors (1999) is used to explore this relation - a final ranking of the alternatives is obtained for each decision maker; (2) from the result obtained by the individual evaluation, an outranking relation is built for the supra decision maker, that is explored, and results in a final ranking of the alternatives.

Macharis \& Brans (1998) developed GDSS PROMETHEE, which has three stages: (1) a preliminary stage, (2) individual evaluation and, (3) global evaluation. The first stage corresponds to the generation of alternatives and criteria - this is the problem structuring stage. In the second stage, each decison maker conducts an evaluation of the alternatives using the PROMETHEE methodology (which could be PROMETHEE I, PROMETHEE II and the GAIA plan) - at the end of which each DM has his/her individual ranking of the alternatives. In the final stage (stage 3), a global matrix of preferences (nxR) is obtained including $\mathrm{n}$ alternatives and $\mathrm{R}$ criteria that correspond to $\mathrm{R} \mathrm{DMs}$, so as to bring together the DMs' points of view. Through the application of a weighting sum of the alternatives evaluation, the alternative is chosen.

The model developed by Alencar \& Almeida (2008) is recommended for those cases where there is great divergence among the decision makers regarding the priorities of the criteria. A matrix of DMs versus Criteria is built. To obtain a collective criteria ranking, the ELECTRE IV method is used. Having obtained this ranking, VIP Analysis (Variable Interdependent Parameters) is applied and the alternatives are selected.

Morais \& Almeida (2007) proposed a group decision making model based on the PROMETHEE V method to provide a management strategy for dealing with leakages from a water network. This model consists of two steps. First, the multicriteria problem is solved by means of the PROMETHEE GDSS procedure so as to examine the preferences of four decision-makers and to obtain a global ranking of alternatives. Secondly, the constraints of the problem are integrated with integer programming, where the objective function is to maximize the sum of the binary variables assigned to the alternatives under consideration, each of which is multiplied by the net flow calculated in the previous step.

Dias \& Clímaco (2005) designed the use of VIP Analysis, which incorporated a complementary approach to dealing with aggregation multicriteria performances by using an addictive value function with imprecise information. The group decision aid method proposed (VIP-G) generates a global decision, where group members reach the final decision based on consensus or on some majority rule (the result is considered acceptable if at least $\alpha \mathrm{K}$ decision-makers agree, considering an " $\alpha$-majority" aggregation operator). This is equivalent to voting, for every conceivable input (or result) whether the group accepts it or not.

Colson (2000) presented ARGOS II (Aid to Ranking to be made by a Group of decision makers using Outranking Support), a GDSS that allows candidates to be ranked by a small group of judges, i.e. decision makers. ELECTRE and PROMETHEE methods are used in the first stage: a multicriteria phase of assessment. Thereafter, the functionalities of the software

Pesquisa Operacional, v.30, n.3, p.687-702, Setembro a Dezembro de 2010 
JUDGES (Colson \& Mareschal, 1994) are used to obtain the collective selections and/or ranking of the candidates. Borda or Condorcet rules, minimum ranking disagreements, minimum absolute deviations, minimum Euclidean distances, or Raynaud's prudent orders are part of ARGOS I, and can be used in ARGOS II to help to compare the rankings obtained through the first stage of the decision process or those provided by the members of the jury.

\section{ELECTRE Methods}

The methods of the ELECTRE (Elimination Et Choix Traduisant la Réalité) family seek to obtain a set of $\mathrm{N}$ alternatives that outrank those which do not belong to the subset $\mathrm{N}$ (Vincke, 1992). It is assumed that the decision-maker is capable of providing intercriteria information, which reflect the relative importance among the $\mathrm{k}$ objectives, i.e., the criteria weights (Roy, 1996). Roy (1996) presents six versions of the ELECTRE family, each of which is applicable to a different case. They are ELECTRE I, II, III, IV, IS and TRI. In this study, versions II and IV are used.

The ELECTRE II method, proposed by Roy (1974) and reported by Vincke (1992) is devoted to the ranking problematic (P. $\gamma$ ) and results in a ranking of non dominated alternatives. The concepts of concordance and discordance are used to rank a set of alternatives. The concordance index $\mathrm{C}(\mathrm{a}, \mathrm{b})$ represents the proportion of weight needed for an alternative $a$ to be preferable to $b$; and the discordance index $\mathrm{D}(\mathrm{a}, \mathrm{b})$ measures the relative disadvantage between two alternatives $a$ and $b$, this being defined as the maximum proportion for each one. The strong and weak concordance and discordance indices $\left(\mathrm{c}_{1}, \mathrm{c}_{2}\right.$ and $\left.\mathrm{d}_{1}, \mathrm{~d}_{2}\right)$ are used to find, respectively, the strong and weak outranking relations $\left(\mathrm{S}^{\mathrm{S}}\right.$ and $\left.\mathrm{S}_{\mathrm{w}}\right)$.

$$
\begin{aligned}
& a S^{S} b \text { iff }\left\{\begin{array}{l}
C(a, b) \geq c_{1} \\
D(a, b) \leq d_{1} \\
\sum_{j: g_{j}(a)>g_{j}(b)} w_{j}>\sum_{j: g_{j}(a)<g_{j}(b)} w_{j}
\end{array}\right. \\
& a S_{w} b \text { iff }\left\{\begin{array}{l}
C(a, b) \geq c_{2} \\
D(a, b) \leq d_{2} \\
\sum_{j: g_{j}(a)>g_{j}(b)} w_{j}>\sum_{j: g_{j}(a)<g_{j}(b)} w_{j}
\end{array}\right.
\end{aligned}
$$

The ranking of alternatives is obtained from two complete preorders (Rank 1 and Rank 2).

To obtain Rank 1, first, formula 1 is used in order to have a set of alternatives (A) that were not strongly outranked by any other. Within this set of alternatives, formula 2 is used and a set of alternatives (B) that are not weakly outranked by any other alternative of set A is obtained. The set $\mathrm{B}$ of alternatives is ranked in first position. The procedure must be repeated to determine which set of alternatives is ranked second and so on, until all the alternatives are ranked.

The second preorder is built starting from the worst class of alternatives (those which do not outrank any other alternative) and finalizing with the best class of alternatives. At the end, according to Vincke (1992), its ranking is inverted. The resulting preorder is obtained by using the average of the preorders initially built. 
The ELECTRE II method was used in the first step of the ARGOS II GDSS (Colson, 2000) to obtain the individual rankings of the DMs. The PROMETHEE I, II and III methods are also used in this stage. At the end of this stage, it is verified if there is concordance regarding the results of those four methods for the DM considered. The result of the first phase is a complete preorder of the alternatives for each DM at the second stage. In the multijudge phase (group of DMs), the collective ranking of the alternatives is obtained, using JUDGES software (Colson \& Mareschal, 1994). In this stage, DMs can make some measurements of similarities or differences between their own and other DMs' rankings.

ELECTRE IV is used in cases in which there is a pseudo-criterion family. Its main feature is related to the non use of a weighting related to the relative importance of the criteria. This is also used for the ranking problematic (P. $\gamma$ ).

The outranking relations are defined by direct reference to the performance levels of the alternatives. Strong and weak outranking relations are built. For an alternative $a$ to outrank an alternative $b$ strongly, it is necessary that (1) for all criteria, there is neither bPa nor bQa, where $\mathrm{P}$ indicates a strict preference and Q indicates a weak preference; or (2) for all criteria, there is no bPa but there could be bQa. However, the criteria set in which there is $\mathrm{aQb}$ or $\mathrm{aPb}$ must be bigger or equal to the set of criteria in which bQa occurs.

For an alternative $a$ to outrank an alternative $b$ weakly, it is necessary that (1) situation 2 of the latter case $\left(\mathrm{aS}^{\mathrm{S}} \mathrm{b}\right.$ ) is not met or that (2) $\mathrm{bPa}$ (in this criterion the difference of $b$ to $a$ must be less than the veto) is in only one criterion and that $\mathrm{aPb}$ is in at least half of the criteria considered.

The exploration of the outranking relations is conducted by using ascending and descending distillation processes, resulting in a ranking of alternatives from the best to worst. The qualification concept is used based on the strong and weak outranking relations to define the two rankings (pre-orders).

The initial qualification of the alternatives is determined by the strong outranking relation. The weak one is used to distinguish, if possible, among those alternatives that have the same value of initial qualification (Vincke, 1992).

In order to explore the outranking relation, the subset of alternatives that have the best qualifications of $a$ for the strong relation is determined. The qualification of $a$ is the number of alternatives outranked by $a$, minus the number of alternatives that outrank $a$. Exclude this subset from the analysis and the procedure is repeated with the set of the remaining alternatives which have a lower degree of qualification. If the subset has more than one alternative, the same procedure is followed in which the weak outranking relation is taken into consideration. This descending procedure is carried out until only one alternative of A remains, and there is a complete preorder. The second preorder is built by a similar procedure, being ascendant, i.e., begin with the set of the worst qualifications (Vincke, 1992).

ELECTRE methods have been applied for several different multicriteria decision problems, such as: for risk analysis (Brito et al., 2010), project management (Mota et al., 2009) and outsourcing (Almeida, 2007). The ELECTRE IV method was used by Alencar \& Almeida (2008) together with Variable Interdependent Parameters analysis (Dias \& Clímaco, 2000) to address those problems of group decision where there is great divergence among the decision makers. 


\section{A multicriteria group decision model aggregating the preferences of decision-makers}

According to Jabeur \& Martel (2007), in the literature on group decision-making, the approach often adopted is that of considering the collective result, obtained by the aggregation of individual preferences, and is the result of consensus. However, in a real group decision-making situation, the collective result may only be accepted by some members, due to the fact that this result is only built by mathematical modelling and, consequently, it is obtained without dialogue, discussion and disputation of ideas among the members. Thus, it is held to be essential that the members participate in an interactive procedure which allows a satisfactory result to be reached.

There are several possible ways to aggregate information when more than one individual participates in a decision process. Forman \& Peniwati (1998) observe that the two methods that have been found to be most useful are those of aggregating individual judgments and individual priorities.

In accordance with such ideas, Dias \& Clímaco (2005) presented illustrations (Figure 1) of both ways of aggregating preferences in group decision-making: as input of data in the model, and as output of the results of the model.
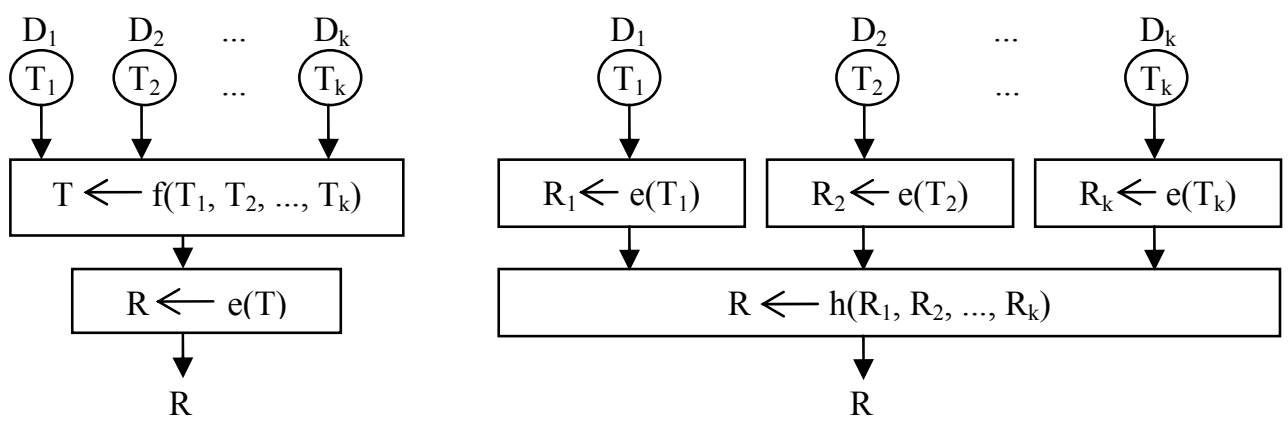

Fig. 1 - Ways of aggregating the individual perspectives (source: Dias \& Clímaco, 2005).

Dias \& Clímaco (2005) described these as follows. Consider a group of $\mathrm{K}$ decision-makers, in which each one has a group of acceptable values for the parameters $\left(T_{k}, k=1,2, \ldots, K\right)$. When the aggregation occurs at the input level (Figure 1(a)), an operator $f($.) brings together the individual judgements $\left(T_{k}\right)$, within a set $T$ of acceptable values for the group, while an operator $e$ (.) generates all the results of the method $\mathrm{R}$ compatible with $\mathrm{T}$. When the aggregation occurs at the output level (Figure 1(b)), the operator $e($.) generates the set of the results of the method compatible with each of the decision-makers $\mathrm{T}_{\mathrm{k}}$, while the operator $h($.) brings together the results of the individual sets $R_{k}$ within a results set $R$.

This paper focuses on the second approach, and proposes a multicriteria group decision model based on ELECTRE II and ELECTRE IV methods, targeting cases in which a divergence occurs among the preferences of the decision-makers and there is no information about their relative importance to each other. 


\section{- Description of the model}

The objective of the model proposed is to support a group of decision-makers to find a satisfactory ranking with regard to a set of possible alternatives, taking into account all their individual preferences and their perceptions about relative importance among criteria. This can be divided into three stages: the individual evaluation, the global matrix with the evaluation of alternatives $x$ decision-makers, and the collective decision with the final ranking.

Once the problem has been structured and both the alternatives as well as the evaluation criteria have been defined, the procedure can be started.

Let $A=\left\{a_{1}, a_{2}, \ldots, a_{i}, \ldots, a_{n}\right\}$ be the set of $n$ alternatives to be evaluated by $k$ criteria $C r=\left\{c r_{l}, c r_{2}, \ldots, c r_{j}, \ldots, c r_{k}\right\}$. A decision matrix $\mathrm{D}=\left[d_{i j}\right]$ can be defined, in which the element $d_{i j}(i=1,2, \ldots, n ; j=1,2, \ldots, k)$ represents the performance evaluation of the alternative $a_{i}$ in accordance with criterion $c_{j}$. As there is the group of decision-makers comprising $D M=\left\{d m_{1}, d m_{2}, \ldots, d m_{r}, \ldots, d m_{R}\right\}$ members, we shall have $\mathrm{R}$ decision matrices $(n \times k)$.

In the first stage of the evaluation, each decision-maker undertakes the evaluation of the alternatives. In this stage what is needed is a method to help the decision-makers provide a ranking of alternatives based on some criteria and which takes into account their relative importance to each other. Thus, we chose to apply the ELECTRE II method. According to Vincke (1992), this method aims to rank a set of alternatives from the best to the worst (ranking problematic - P. $\gamma$ ), concerning problems involving true criteria. The outranking relation is built by using the concordance index (measuring the arguments in favor of the statement ' $a$ is at least as good as $b$ ') and the discordance index (measuring the arguments that may shed some doubt upon the latter statement). The ranking is found by means of building two pre-orders on the basis of a strong $\left(\mathrm{S}^{\mathrm{S}}\right)$ and a weak $\left(\mathrm{S}_{\mathrm{w}}\right)$ outranking relation, whereby strong and weak rankings are deduced to obtain the final ranking. At the end of this stage, each decision-maker has his/her own ranking of the alternatives, representing their personal points of view (PV). Although the ELECTRE III method was considered, as it is also a method for ranking problems, ELECTRE II was chosen because it uses true criteria, while ELECTRE III uses pseudo-criteria. The PROMETHEE II method can also be used in this stage since it can use true criteria and the result also provides a complete preorder.

In the second stage of evaluation, a global matrix of preferences $(n \times R)$ is obtained, representing the $n$ alternatives and the $R$ decision-makers, in such a way as to coalesce the decision-makers' points of view. The performances of the alternatives per decision-maker are given by the ranking obtained in the preorder resulting from the latter stage. Thus, once the individual matrices have been evaluated, the points of view resulting from each group member will comprise a new matrix $\mathrm{G}=\left[g_{i r}\right]$, in which the element $g_{i r}$ $(i=1,2, \ldots, n ; r=1,2, \ldots, R)$ represents the position of the alternative $a_{i}$ calculated on the basis of the decision-maker's preferences $d m_{r}$.

The third stage corresponds to the aggregation of the individual preferences, i.e. the individual rankings. In this stage, a method is needed to provide the global ranking of alternatives, which considers the decision-makers as criteria. Thus, we chose to apply ELECTRE IV in order to obtain a final ranking of the alternatives. The choice of this method is justified by the fact of there not being any knowledge with regard to the relative importance of the decision-makers to each other. According to Vincke (1992), the objective of ELECTRE IV is to rank the actions without introducing any weighting of the criteria,

Pesquisa Operacional, v.30, n.3, p.687-702, Setembro a Dezembro de 2010 
namely, it is admitted that there is not sufficient or perfect information with regard to the relative degrees of importance among the criteria. Thus, ELECTRE IV is suitable for this case, since it permits a set of alternatives to be ranked in situations in which it is difficult to define a ratio of importance among the criteria, which in this stage are represented by the decision-makers. This method is based on a non-compensatory logic, in which the criteria (decision-makers) are compared to each other one by one, which allows these types of problems to be dealt with coherently, especially when it is difficult to establish weights among the decision-makers. The outranking ratio is defined by direct reference to the performances of the alternatives, these being defined as ratios of strong or weak outranking. As a final result, the ranking of the alternatives is reached.

The model is shown in the following diagram (Figure 2).

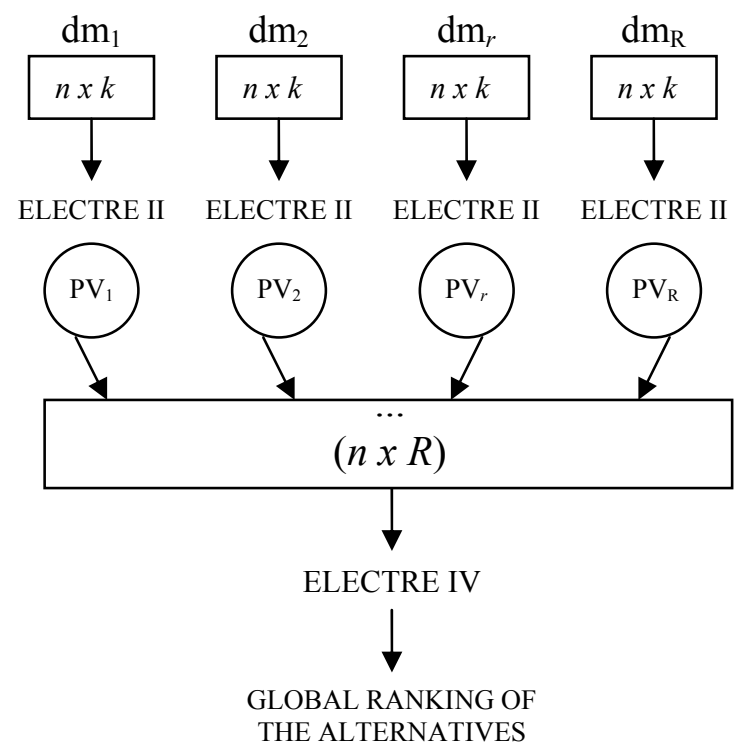

Fig. 2 - Multicriteria group decision model aggregating decision-makers' evaluations of the alternatives.

One matter to be considered is that in this situation of aggregating the decision-makers, the use of non-compensatory methods is suggested. Since each decision-maker is considered a criterion, and the evaluations of the alternatives reflect their preferences, compensatory aggregation may generate a result which may not satisfy the decision-makers. However, as the non-compensatory method compares the criteria one by one, this type of problem is dealt with coherently.

Another matter to be considered is that in the first step of the model, in which the decisionmakers' individual evaluations are undertaken, any other multicriteria method appropriate for ranking a problem can be used, since in the second stage the input data are the rankings of the alternatives. In other words, not only methods that show an ordinal scale, but also those that give a value-measured result can be applied to build the individual rankings. 


\section{Numerical application}

By way of illustration, the multicriteria group decision model presented in the previous section is used in order to select sub-contractor companies for construction projects. The structuring of the problem is the same as Alencar \& Almeida (2008) had done, but the problem is to select sub-contractors and not contractors. The 2008 article is used as a reference for the numerical application and thereafter, for the application in accordance with the three stages of the model.

\subsection{Structuring of the problem}

Once the contractor and consultants are established, the process of selecting the companies that will be outsourced can be initiated.

First, the contractor needs to identify the activities that should be subcontracted for that project. Thereafter, sub-contractor companies will be invited to participate in the selection process.

There is also a need to identify the evaluation criteria to be considered in the selection process. First of all, the group of decision-makers (DMs) who will decide on these criteria is formed. They are $D_{1}, D_{2}$ and $D_{3}$, the representatives of the contractor company; $D_{4}$ - the representative of the consultants' company, and; $D_{5}-$ the client representative of the Dept of Engineering.

The qualifying and bid winner criteria are identified. Only the responsibility criterion was chosen as the qualifying one - the evaluation is with regard to the existence of quality, safety and environmental certification and fulfilling the regulations and the standards required. The criteria for and deciding on bid winners are Cost $\left(\mathrm{Cr}_{1}\right)$, Culture $\left(\mathrm{Cr}_{2}\right)$, Design $\left(\mathrm{Cr}_{3}\right)$, Quality $\left(\mathrm{Cr}_{4}\right)$, Time $\left(\mathrm{Cr}_{5}\right)$ and Experience $\left(\mathrm{Cr}_{6}\right)$.

The analyst conducts the evaluations of the criteria $\mathrm{Cr}_{2}, \mathrm{Cr}_{3}$ and $\mathrm{Cr}_{4}$ because this involves making a technical evaluation of subjective judgments.

Once the criteria have been defined, the next step is to establish the relative importance between them. The methodology used is that of direct attribution - first of all the decisionmaker is asked to order the criteria in descending order, i.e. those which are judged as the most important obtain the best position, it being permitted to have two in the same position; thereafter, each DM is questioned about what weights should be attributed to each criterion.

\subsection{1st Stage of the model}

The first stage comprises the individual evaluations of each decision-maker. The evaluation matrix is the same for all decision-makers since there is no change regarding the companies' evaluation in each criterion for each DM. The individual evaluations are given regarding the weighting of the criteria and the concordance and discordance coefficients.

The evaluation matrix and the concordance and discordance coefficients with their corresponding parameters are shown below, namely in Tables 1 and 2, respectively.

Pesquisa Operacional, v.30, n.3, p.687-702, Setembro a Dezembro de 2010 
Table 1 - Decision matrix: Alternatives x Criteria.

\begin{tabular}{ccccccc}
\hline & $\mathrm{cr}_{1}$ & $\mathrm{cr}_{2}$ & $\mathrm{cr}_{3}$ & $\mathrm{cr}_{4}$ & $\mathrm{cr}_{5}$ & $\mathrm{cr}_{6}$ \\
\hline Company A & 0.10 & 3 & 4 & 4 & 0.10 & 8 \\
Company B & 0.20 & 2 & 2 & 4 & 0.05 & 10 \\
Company C & 0.15 & 1 & 3 & 3 & 0.00 & 5 \\
Company D & 0.01 & 2 & 1 & 4 & 0.15 & 6 \\
Company E & -0.03 & 4 & 4 & 3 & 0.20 & 10 \\
Company F & 0.03 & 2 & 3 & 3 & 0.30 & 5 \\
\hline
\end{tabular}

Table 2 - Concordance $\left(c_{1}\right.$ and $\left.c_{2}\right)$ and discordance $\left(d_{1}\right.$ and $\left.d_{2}\right)$ coefficients for each decision-maker.

\begin{tabular}{ccccc}
\hline & $\mathrm{c}_{1}$ & $\mathrm{c}_{2}$ & $\mathrm{~d}_{1}$ & $\mathrm{~d}_{2}$ \\
\hline $\mathrm{dm}_{1}$ & 0.7 & 0.6 & 0.4 & 0.5 \\
$\mathrm{dm}_{2}$ & 0.8 & 0.6 & 0.3 & 0.4 \\
$\mathrm{dm}_{3}$ & 0.8 & 0.6 & 0.3 & 0.4 \\
$\mathrm{dm}_{4}$ & 0.8 & 0.6 & 0.3 & 0.4 \\
$\mathrm{dm}_{5}$ & 0.9 & 0.6 & 0.4 & 0.5 \\
\hline
\end{tabular}

The inter-criteria information (criteria weights) regarding the point of view of each decisionmaker is presented in Table 3 below.

Table 3 - Table of normalized weights of each decision-maker's criteria.

\begin{tabular}{ccccccc}
\hline & $\mathrm{cr}_{1}$ & $\mathrm{cr}_{2}$ & $\mathrm{cr}_{3}$ & $\mathrm{cr}_{4}$ & $\mathrm{cr}_{5}$ & $\mathrm{cr}_{6}$ \\
\hline $\mathrm{dm}_{1}$ & 0.091 & 0.182 & 0.182 & 0.227 & 0.136 & 0.182 \\
$\mathrm{dm}_{2}$ & 0.087 & 0.130 & 0.261 & 0.217 & 0.043 & 0.261 \\
$\mathrm{dm}_{3}$ & 0.067 & 0.267 & 0.267 & 0.200 & 0.067 & 0.133 \\
$\mathrm{dm}_{4}$ & 0.333 & 0.000 & 0.133 & 0.133 & 0.333 & 0.067 \\
$\mathrm{dm}_{5}$ & 0.417 & 0.000 & 0.000 & 0.167 & 0.333 & 0.083 \\
\hline
\end{tabular}

Armed with this information, the ELECTRE II methodology is applied, and a ranking of the Companies based on two preorders (one ascending and the other descending) is obtained for each decision-maker.

The preorders obtained for each decision-maker are illustrated in Table 4.

Table 4 - Table of preorders obtained for each decision-maker.

\begin{tabular}{rccccc}
\hline & $\mathrm{dm}_{1}$ & $\mathrm{dm}_{2}$ & $\mathrm{dm}_{3}$ & $\mathrm{dm}_{4}$ & $\mathrm{dm}_{5}$ \\
\hline $1^{\text {st }}$ & $\mathrm{B}, \mathrm{C}, \mathrm{E}$ & $\mathrm{A}$ & $\mathrm{A}$ & $\mathrm{B}, \mathrm{D}$ & $\mathrm{A}, \mathrm{B}$ \\
$2^{\text {nd }}$ & $\mathrm{A}, \mathrm{D}, \mathrm{F}$ & $\mathrm{E}, \mathrm{F}$ & $\mathrm{B}, \mathrm{C}, \mathrm{D}, \mathrm{E}, \mathrm{F}$ & $\mathrm{A}, \mathrm{C}, \mathrm{E}, \mathrm{F}$ & $\mathrm{C}, \mathrm{D}, \mathrm{E}, \mathrm{F}$ \\
$3^{\text {rd }}$ & & $\mathrm{B}, \mathrm{C}, \mathrm{D}$ & & & \\
\hline
\end{tabular}




\subsection{2nd Stage of the model}

In this second stage, the analyst should collect the rankings obtained from each DM, which represent their preferences, and should compile a global evaluation matrix, in which each DM is considered as a criterion and the rankings of each DM correspond to the evaluations of the alternatives, as shown in Table 5. The higher the numerical evaluation of a given alternative, the better is its position in the pre-order.

Table 5 - Matrix of global evaluation.

\begin{tabular}{cccccc}
\hline & $\mathrm{dm}_{1}$ & $\mathrm{dm}_{2}$ & $\mathrm{dm}_{3}$ & $\mathrm{dm}_{4}$ & $\mathrm{dm}_{5}$ \\
\hline Company A & 2 & 3 & 3 & 2 & 3 \\
Company B & 3 & 1 & 2 & 3 & 3 \\
Company C & 3 & 1 & 2 & 2 & 2 \\
Company D & 2 & 1 & 2 & 3 & 2 \\
Company E & 3 & 2 & 2 & 2 & 2 \\
Company F & 2 & 2 & 2 & 2 & 2 \\
\hline
\end{tabular}

\subsection{3rd Stage of the model}

In this third stage, ELECTRE IV is applied, since it does not need inter-criteria information, and provides the ranking of the Companies.

As the evaluation of the alternatives corresponds to the position of the alternatives, any difference between them implies a strict preference. Thus, all the thresholds of indifference and preference, for each criterion, are equal to zero.

By applying ELECTRE IV, the following ranking is obtained, as shown in Table 6.

Table 6 - Ranking of the alternatives.

\begin{tabular}{cc}
\hline Ranking & Alternative \\
\hline $1^{\text {st }}$ & B \\
$2^{\text {nd }}$ & A, E \\
$3^{\text {rd }}$ & D \\
$4^{\text {th }}$ & C, F \\
\hline
\end{tabular}

Thus, according to the DMs' preferences, Company B is ranked first and the Companies A and $\mathrm{E}$ are in equal second position.

Since company B is the only one selected, it receives the project, analyzes it and discusses it together with the contractor and the consultants. After that, its proposal is submitted to the contractor and the contract is signed. In the case of considering the first and second positions in the ranking, companies A, B and E would proceed to the phases of submitting cost, time and quality proposals, of concurrent engineering, of revising their proposals and of final selection based on cost, time and quality. 


\subsection{Results: a comparison with other methods}

The problem of aggregating the individual pre-orders of decision-makers in a single collective pre-order has been the target of several studies in the literature on group decisionmaking. Historically, the first papers which tackled this problem were by Borda (1781) and by Condorcet (1785). In the last decade, various studies have been undertaken (Jabeur \& Martel, 2004; Sun \& Greenberg, 2006; Matsatsinis et al., 2005).

The Borda count is a simple procedure of positional voting method where the individual preferences determine the scores of alternatives and the alternative with the largest sum of scores is the Borda winner. To use this method one needs to rank the alternatives by preferences, without any decision aid method. The individual should put the alternatives in order of priorities for each criterion. However, no evaluation is made of the relative importance among criteria.

Condorcet performs a pair comparison of alternatives to verify which one was preferred by the majority of the decision-makers. This is known as the simple majority rule method. It is sometimes considered as fairer because it does evaluate the relation among alternatives, but it has the disadvantage of leading to situations of intransitivity.

Since, in the first stage of the model, intercriteria information is needed, i.e., the relative importance among criteria, and the DMs need to know how to analyze them, the use of methods such as the Borda and Condorcet ones are not suitable in these cases.

In order to analyze the result of the last stage of the model proposed, a comparison is made with other methods such as Borda's and Condorcet's to investigate the performance of the proposed method. Table 7 shows the results.

Table 7 - Comparison of the results from the proposed method and other methods.

\begin{tabular}{c|c|c|c}
\hline Methods & Proposed Method & Borda & Condorcet \\
\hline $1^{\text {st }}$ & B & A & A, B \\
$2^{\text {nd }}$ & A, E & B & E \\
$3^{\text {rd }}$ & D & E & C, D, F \\
$4^{\text {th }}$ & C, F & C, D, F & \\
\hline
\end{tabular}

As can be seen, in the three methods presented, alternatives A, B and E are ranked ahead of $\mathrm{C}, \mathrm{D}$ and F. As the Borda method is a simple voting count, it is easy to perceive that alternative $\mathrm{A}$ is the winner since this alternative is ranked first by three DMs and second by two of them; while B although ranked first by three DMs is ranked second by only one of them.

However, in the proposed method, alternative B is in first position. This happened because ELECTRE IV uses the criteria associated with a preference threshold and with an indifference threshold, instead of using the concordance and discordance indices. In this case, it is more advantageous for the DMs that they can establish, in consensus, the parameters for the model. For the parameters established for this application, the results of descending and ascending distillation are shown in Figure 3. 

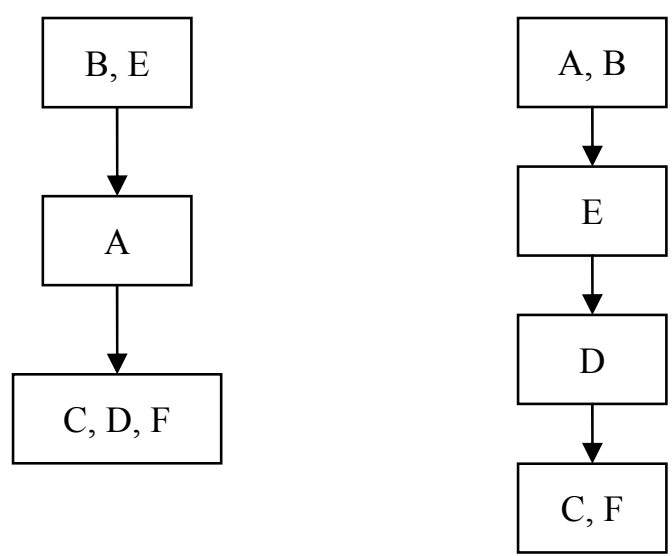

Fig. 3 - Descending and Ascending Distillations.

With this result, it can be seen that alternative B is in first position.

Condorcet, at this point, presented more ties. As Condorcet makes only a pairwise comparison, counting how many votes one alternative has with regard to another, alternatives A and B are shown as tied in first position. This happened because alternative A is better than B for two DMs and alternative B is also better than A for two DMs; and for one DM they are tied. So, the final result is the same position for both alternatives.

In conclusion, it can be said that the ELECTRE IV method has an advantage over the methods analysed since the final preorder obtained is a result of evaluating two preorders obtained by analyzing strong and weak outranking relations and carrying out descending and ascending distillations.

\section{Conclusion}

In general, decisions made in organizations involve a group of people, from different departments or sectors, and indeed, as in our case study, from the consultancy company, contractor company and the client's representatives, to guarantee that the client's interests are as well represented as possible. Many papers in the literature do not adequately tackle the question of group decision, and moreover, many group decision problems are modeled as if a single person were responsible for that decision even though this does not correspond to reallife situations.

This paper has presented a group decision multicriteria model for situations where there is divergence among the decision-makers' preferences. In this model, the decision-makers' evaluations of the alternatives are undertaken individually, using ELECTRE II, and later aggregated. Thereafter a final ranking of the alternatives which are being evaluated is obtained.

This final ranking can be undertaken through use of the ELECTRE IV method which ranks the actions without introducing any weighting of the criteria, that is, it is admitted that there is not sufficient or perfect information with regard to the relative importance among the decision-makers. Thus, ELECTRE IV has been shown to be very appropriate for this situation in which there is no clear distinction between the importance of the decision-makers. 
Two models were found in the literature that used the ELECTRE II and ELECTRE IV methods for group decision. The model that uses ELECTRE II is used in the same way as the model presented in this paper: to provide individual rankings of the DMs. Nevertheless, in the second stage of the model they use a social choice function to compare the rankings provided by the DMs together with visual tools. In this paper, the ELECTRE IV method is used in the second stage that will unite the information of the group of DMs in order to obtain a final ranking which takes into consideration the preferences of all of them, without it being necessary to differentiate between their importance.

In the second model, the authors use ELECTRE IV method for the first stage of the model to obtain the ranking of the criteria based on the preferences of the DMs to be used in the next stage. In this paper, as was presented above, ELECTRE IV is used in the last stage to obtain the ranking of the alternatives and takes the DMs' preferences into consideration.

It should be pointed out that during our review of the literature, no model was found that evaluates the combination of methods proposed in this paper.

Finally, it is important to note that other simple methods such as the Borda count and Condorcet could be used in the last stage of the proposed method, since, in that stage, the evaluation of weight among decision-makers is not necessary. In other words, no subjective parameter to use the model is re quired. However, these methods are based only on the ranking position and this is a disadvantage because lose information. Thus, the use of ELECTRE IV is more appropriate in this situation since it uses the criteria associated with a preference threshold and with an indifference threshold, instead of using the concordance and discordance indices.

\section{Acknowledgments}

This study is part of a research program funded by the Brazilian Research Council (CNPq). The authors gratefully acknowledge the valuable suggestions made by anonymous reviewers to a previous version of this paper, which have contributed to making this a better final version.

\section{References}

(1) Alencar, L.H. \& Almeida, A.T. (2008). Multicriteria Decision Group Model for Suppliers Selection. Pesquisa Operacional, 28(2), 321-337.

(2) Almeida, A.T. (2007). Multicriteria decision model for outsourcing contracts selection based on utility function and ELECTRE method. Computers and Operations Research, 34(12), 3569-3574.

(3) Beynon, M.J. (2006). The Role of the DS/AHP in identifying inter-group alliances and majority rule within group decision making. Group decision and negotiation, 15(1), 21-42.

(4) Borda, J.C. (1781). Mémoire sur les élections au scrutin. Histoire de l'Académie Royale des Sciences, Paris. Apud Cook, W.D. (2006). Distance-based and ad hoc consensus models in ordinal preference ranking. European Journal of Operational Research, 172, 369-385. 
(5) Brito, A.J.; de Almeida, A.T.; Mota, C.M. (2010). A multicriteria model for risk sorting of natural gas pipelines based on ELECTRE TRI integrating utility theory. European Journal of Operational Research, 200, 812-821.

(6) Clímaco, J.C. \& Dias, L.C. (2005). An approach to support negotiation processes with imprecise information multicriteria additive models. In: Workshop on formal and informal information exchange in negotiations. Proceedings... School of Information Technology and Engineering, University of Ottawa.

(7) Colson, G. (2000). The OR's prize winner and the software ARGOS: how a multijudge and multicriteria ranking GDSS helps a jury to attribute a scientific award. Computers and Operations Research, 27, 741-755.

(8) Colson, G. \& Mareschal, B. (1994). JUDGES: a descriptive group decision support system for the ranking of items. Decision Support System, 12, 391-404.

(9) Condorcet, M. (1785). Éssai sur l'application de l'analyse à la probabilité des décisions rendues à la pluralité des voix. De l'imprimirie, Paris. Apud Yong, H.P. (1988). Condorcet's theory of voting. The American Political Science Review, 82(4), 1231-1244.

(10) Costa, J.P. et al. (2003). The AGAP System: A GDSS for project analysis and evaluation. European Journal of Operational Research, 145(2), 287-303.

(11) Dias, L.C. \& Climaco, J.N. (2000). Electre Tri for Groups with imprecise information on parameter values. Group and Negotiation, 9(5), 355-377.

(12) Dias, L.C. \& Clímaco, J.N. (2000). Additive aggregation with variable interdependent parameters: the VIP Analysis software. Journal of the Operational Research Society, 51, 1070-1082.

(13) Dias, L.C. \& Climaco, J.N. (2005). Dealing with imprecise information in group multicriteria decisions: a methodology and a GDSS architecture. European Journal of Operational Research, 160, 291-307.

(14) Easley, R.F.; Valacich, J.S. \& Venkataramanan, M.A. (2000). Capturing group preferences in a multicriteria decision. European Journal of Operational Research, 125, 73-83.

(15) Forman, E. \& Peniwati, K. (1998). Aggregating individual judgments and priorities with the analytic hierarchy process. European Journal of Operational Research, 108(1), 165-169.

(16) Humphreys, P. \& Garrick, J. (2006). The evolution of group decision support systems to enable collaborative authoring of outcomes. The Journal of General Evolution, 62(3), 193-222.

(17) Jabeur, K. \& Martel, J.M. (2004). A distance-based collective preorder integrating the relative importance of the group's members. Group Decision and Negotiation, 13, 327-349.

(18) Jabeur, K. \& Martel, J.M. (2007). A collective choice method based on individual preferences relational systems (p.r.s.). European Journal of Operational Research, 177, $1549-1565$.

(19) Jelassi, T.; Kersten, G. \& Ziont, S. (1990). An introduction to group decision and negotiation support. In: Readings in multiple criteria decision aid [edited by Bana e Costa], Springer-Verlag, Berlin, 537-568.

Pesquisa Operacional, v.30, n.3, p.687-702, Setembro a Dezembro de 2010 
(20) Kim, S.H. \& Ahn, B.S. (1999). Interactive group decision making procedure under incomplete information. European Journal of the Operational Research, 116, 498-507.

(21) Leyva-López, J.C. \& Fernández-Gonzalez, E. (2003). A new method for group decision support based on ELECTRE III methodology. European Journal of Operational Research, 26(3).

(22) Macharis, C. \& Brans, J.P. (1998). The GDSS PROMETHEE procedure. Journal of Decision Systems, 7, 283-307.

(23) Matsatsinis, N.F.; Grigoroudis, E. \& Samaras, A. (2005). Aggregation and disaggregation of preferences for collective decision-making. Group Decision and Negotiation, 14(3), 217-232.

(24) Morais, D.C. \& Almeida, A.T. (2007). Group Decision-Making for Leakage Management Strategy of Water Network. Resources, Conservation and Recycling, 52, 441-459.

(25) Mota, C.M.M.; Almeida, A.T. \& Alencar, L.H. (2009). A multiple criteria decision model for assigning priorities to activities in project management. International Journal of Project Management, 27(2), 175-181.

(26) Roy, B. (1996). Multicriteria Methodology for Decision Aiding. Kluwer Academic Publishers, Boston.

(27) Sun, L. \& Greenberg, B.S. (2006). Multicriteria Group Decision Making: optimal priority synthesis from pairwise comparisons. Journal of Optimization Theory and Applications, 130(2), 317-338.

(28) Vincke, P. (1992). Multicriteria decision-aid. John Wiley \& Sons, Bruxelles. 